\title{
DEBATES
}

\section{Comunitarismo e Capital Social: convergências}

\section{Communitarianism and social capital: convergences}

\section{João Pedro Schmidt}

\section{Resumo}

O paradigma comunitarista, na formulação de Amitai Etzioni, tem como uma de suas teses centrais o equilíbrio entre Estado, comunidade e mercado. O problema que conduz a presente investigação é se o paradigma comunitarista constitui uma moldura conceitual condizente com os pressupostos das teorias do capital social. A resposta é positiva, ao considerar que a tese do equilíbrio das três esferas recusa a ênfase unilateral na força coercitiva do Estado ou na auto regulação do mercado e confere papel central à comunidade como espaço de criação e recriação dos valores que orientam a vida em sociedade. $\mathrm{O}$ método é dedutivo e a técnica de pesquisa é bibliográfica.

\section{Palavras-chave}

Comunitarismo; Capital Social; Estado; Comunidade; Mercado.

\begin{abstract}
The communitarian paradigm, as formulated by Amitai Etzioni, has as one of its central theses the balance between State, community and market. The problem addressed in this research is that if the communitarian paradigm is a conceptual framework consistent with the assumptions of theories of social capital. The answer is positive, considering that the thesis of the balance of the three spheres rejects the unilateral emphasis on the coercive power of the state and the self-regulation of the market, and provides a central role to the community as a space of creation and recreation of the values that guide life in society. The method is deductive and the research technique is a review of the aliterature.
\end{abstract}

\section{Keywords}

Communitarianism; Social Capital; State; Community; Market. 


\section{Introducão}

A relação entre Estado e mercado tem sido objeto de intensos debates políticos referentes à democracia, ao desenvolvimento e à inclusão social. Em determinados momentos, prevaleceu o otimismo acerca do protagonismo estatal no campo econômico e social, como nas décadas de consolidação do Estado de BemEstar (welfare state) no pós-2a Guerra Mundial; em outros, as críticas aos excessos do intervencionismo estatal e à necessidade de liberalizaçáo dos mercados, como nas décadas de 1980 e 1990. Ao primeiro momento correspondem concepçóes como o socialismo, a social-democracia e o nacional-desenvolvimentismo; ao segundo, o liberalismo e neoliberalismo. O pêndulo tem oscilado entre o estatal e o privado.

Essa bipolaridade é um dos elementos da atual crise do pensamento político e econômico (SEVILHA e QUIRÓS, 2010). Com a queda dos regimes socialistas do Leste Europeu, as dificuldades recorrentes dos regimes de welfare state na Europa e o evidente insucesso das reformas neoliberais em termos econômicos e sociais, há uma atenção crescente a modelos alternativos, entre elas a concepção comunitarista. No ambiente acadêmico brasileiro, tanto o comunitarismo norte-americano (que inclui autores como Amitai Etzioni, Robert Bellah, Philip Selznick, Wiliam Galston, Benjamin Barber, James Fishkin, Amy Gutman, Mary Ann Glendon e Thomas Spragens) como o britânico (com autores como Henry Tam, Jonathan Boswel, John Gray, David Miller, Elizabeth Frazer, Nicola Lacey e Michael Taylor) estão praticamente ausentes nos estudos acadêmicos. As referências ao comunitarismo em geral resumem-se aos filósofos Michael Sandel, Michael Walzer, Charles Taylor e Alasdair MacIntyre, que proporcionaram densidade teórica ao pensamento comunitarista, mas não esgotam seu vasto repertório conceitual.

A grande contribuição do comunitarismo está em (re)posicionar a comunidade como princípio político, alicerçando uma concepção contraposta ao dualismo público/privado, ao estatismo (exagerada confiança nas virtudes do Estado) e ao privatismo (excessiva confiança nas virtudes do livre mercado e da iniciativa privada).

O presente artigo explana a tese comunitarista do equilíbrio entre Estado, comunidade e mercado, e analisa a sua convergência com o conceito de capital social. O problema aqui enfrentado é: a tese comunitarista da complementaridade das esferas estatal, comunitária e privada é compatível com os pressupostos do capital social? O método é dedutivo e a técnica de pesquisa é bibliográfica. 


\section{A tese comunitarista do equilíbrio entre Estado, comunidade e mercado}

O comunitarismo responsivo (responsive, em inglês, no sentido de sensível às demandas dos cidadãos) é um movimento intelectual articulado inicialmente nos Estados Unidos, cujas diretrizes foram divulgadas, em 1991, no manifesto The Responsive Communitarian Platform, com ramificaçóes em diversos países. Suas premissas se contrapóem frontalmente ao neoliberalismo, por um lado, e ao conservadorismo, por outro, e estão assentadas no pensamento comunitário ocidental, que remonta a Aristóteles, à tradição judaico-cristã e à tradição republicana (SANDEL, 2008; ETZIONI, 2006 e 2014; SCHMIDT, 2011 e 2014).

A grande bandeira política do movimento comunitarista responsivo é o fortalecimento das comunidades nas sociedades ocidentais, marcadas pelo individualismo. Esse fortalecimento materializa-se em políticas públicas que reforçam a vivência comunitária, incorporam agentes e organizaçôes comunitárias nas decisóes públicas e delegam serviços de interesse coletivo às comunidades, sempre que tiverem condiçôes adequadas de executá-los. Delegar serviços de interesse público às organizaçôes comunitárias nada tem a ver com "Estado mínimo" ou rejeição ao Estado de Bem-Estar. Ao contrário, diz Etzioni (2001a, p. 30), "precisamente na medida em que as comunidades contribuem para reduzir a carga que suporta o estado de Bem-Estar, estarão contribuindo para preservá-lo”.

A tese em questão pode ser sintetizada da seguinte forma: a boa sociedade requer o equilíbrio de três sócios - o Estado, a comunidade e o mercado -, um tripé em que cada parte deve cuidar que "as demais não ultrapassem suas funçôes, para assegurar que ninguém usurpe a tarefa que outro pode realizar melhor" (ETZIONI, 2001a, p. 75). Não se trata de uma fórmula matemática que se aplique do mesmo modo a todos os países: é uma ideia norteadora, que tem implicaçóes distintas de um país a outro. Nas sociedades asiáticas é proeminente a força dos valores coletivos e da coesão social, em detrimento dos valores individuais; nelas, o equilíbrio do tripé requer o reforço da autonomia individual. Nos países do socialismo estatizante, a onipresença do Estado invade a seara da sociedade civil e do mercado: neles, impóe-se uma maior autonomia dessas duas esferas. Nas sociedades ocidentais atuais, marcadamente individualistas, o aparato estatal e os mecanismos de mercado são extremamente avantajados: aqui é preciso reforçar as comunidades e suas organizaçóes (ETZIONI, 1999, 2001a e 2007).

Em resumidas contas, o Estado deve, principalmente, regular o mercado e cuidar de serviços essenciais (defesa, segurança, saúde e proteção ambiental). $\mathrm{O}$ mercado é o melhor motor para a produção da maior parte de bens e serviços. A 
comunidade é o espaço de criação e recriação de valores morais, que confere impulso às mudanças sociais e à melhor alternativa para a prestação de diversos serviços sociais.

\section{O papel do Estado}

A concepção comunitarista do Estado tem na ideia de bem comum um de seus pressupostos centrais. Diferentemente da "política da neutralidade" do liberalismo, os comunitários defendem uma "política do bem comum" (SANDEL, 2008; TAYLOR, 2000; GARGARELLA, 2008). A política do bem comum nada tem a ver com visóes autoritárias, totalitárias ou teocráticas, nas quais o Estado exerce um amplo controle sobre a forma de pensar e sobre as preferências das pessoas. Ela traduz-se no compromisso do Estado com um "conjunto central de valores" (ETZIONI, 2005), definido com base no diálogo moral entre os membros da comunidade. Entre esses valores estáo o compromisso com as comunidades, a participaçáo nos assuntos públicos, a proteção do meio ambiente, o respeito aos direitos humanos, a garantia de uma renda mínima para todos, a harmonizaçáo entre o interesse coletivo e a liberdade individual, e a construção da unidade respeitando à diversidade.

A concepçáo comunitarista do Estado leva em contra três aspectos centrais: (i) o Estado cumpre funçôes indispensáveis na sociedade; (ii) as instâncias estatais se enrijecem ao longo do tempo e tendem a entrar em dissintonia com as coletividades sociais; (iii) as sociedades pós-modernas requerem um Estado de novo tipo, flexível, responsivo às demandas sociais, inovador quanto às formas de prestaçáo de serviços públicos (ETZIONI, 1980). O Estado é "um instrumento importante para a transformação societal e para a redistribuição, aprovada societalmente, da riqueza e status" e tem uma função "permanente na proteção dos direitos do homem e do cidadão e na contenção do conflito armado intrassocietal” (ETZIONI, 1980, p. 581).

Mesmo um "bom" Estado tem claros limites. É imperioso reconhecer que a visão "dirigista" do Estado é inapropriada para dar conta das complexidades das sociedades contemporâneas, assim como é inapropriada da concepção do mercado autorregulado. $\mathrm{O}$ papel do Estado em grande medida é o de articular a cooperação pública entre os entes estatais, sociais e privados (BOSWELL, 1990). Nas mudanças culturais profundas, necessárias para enfrentar crises civilizacionais, o papel do Estado e das lideranças políticas é secundário: o papel principal cabe aos movimentos sociais e à esfera comunal (ETZIONI, 2009b). "O Estado, portanto, nem é a fonte de todo mal societal - como o tem considerado grande parte da tradiçáo ocidental - nem a grande esperança da justiça e cidadania universal” (ETZIONI, 1980, p. 581). O 
Estado desejável é flexível, responsivo e construtor da igualdade de poder entre as coletividades sociais. A rigidez e a centralização das instituiçôes dos regimes de welfare state devem ser substituídas por estruturas estatais responsivas aos cidadáos, aproximando as comunidades do poder público através de mecanismos de cooperação entre o setor público, o setor privado e o terceiro setor (ETZIONI, 1980, 1999 e 2007; SANDEL, 2012; BARBER, 2000).

No âmbito da economia, o Estado tem uma função regulatória insubstituível. A linha de raciocínio comunitarista vai ao encontro da perspectiva traçada por Karl Polanyi, para quem a história econômica comprova que "o mercado foi a consequência de uma intervençáo consciente, e às vezes violenta, por parte do governo que impôs à sociedade a organização do mercado, por finalidades não econômicas" (POLANYI, 2000, p. 290). O Estado Social representa um marco de conquistas inéditas em termos de direitos e proteção social. Além das clássicas funçôes soberanas do Estado liberal, o Estado Social adentrou em novos territórios, absorvendo parcialmente funçóes desempenhadas anteriormente pelas comunidades (saúde, assistência, educação) e pelo mercado. A proteção social teve como contrapartida um notável aumento do gasto público. Thomas Piketty (2014, p. 462) assinala que a receita fiscal nos países ricos até os anos 1910 não ultrapassava $10 \%$ da renda nacional, destinada na maior parte às funçôes soberanas (política, justiça, exército, relaçóes exteriores e administração); a partir daí, evoluiu progressivamente até o patamar de $40 \%$ a $50 \%$ nos anos 1970, sustentando os serviços de educação e saúde $(10 \%$ a $15 \%)$ e as rendas de substituição e transferência - aposentadoria, pensóes, seguro-desemprego e renda mínima (10\% a 20\%). Esses índices atestam que não deixa de ser uma espécie de "esquizofrenia" a posição dos ultraliberais de querer serviços de Estado Social com impostos de Estado liberal ${ }^{1}$.

A crise econômica da década de 1970 criou o ambiente para agudas críticas ao Estado Social, advindas especialmente de críticos neoliberais que denunciaram o gigantismo estatal, a elevada carga tributária, a perda de competitividade daí decorrente, a burocratização excessiva, a má qualidade e a ineficiência dos serviços públicos. Os comunitaristas, que confrontaram abertamente o neoliberalismo e os pressupostos do homo economicus, não deixam de reconhecer que há um conjunto de problemas reais nos regimes de welfare state, como as decisóes excessivamente

\footnotetext{
${ }^{1}$ Etzioni refere-se frequentemente à esquizofrenia de que se reveste a posição ultraliberal: "por um lado, (norte)americanos demandam impostos baixos e governo enxuto, mas de outro exigem uma ampla gama de serviços públicos nas áreas de educação, habitação e políticas de saúde" (ETZIONI, 2009b, p. 156).
} 
centralizadas, a burocracia estatal desmesurada, a falta de transparência e a incapacidade de enfrentar problemas cruciais, como a questão ambiental.

O Estado deve articular as políticas públicas, mas a experiência histórica indica que a prestação estatal de todos os serviços públicos não é recomendável, tanto por razóes de eficácia como de eficiência. Os comunitaristas enfatizam que as políticas sociais, em especial, são um espaço em que as comunidades e as organizaçóes comunitárias podem desempenhar funções mais destacadas, não sendo necessário sequer que o Estado seja a principal fonte desses serviços. Há um importante repertório de alternativas comunitárias construídas historicamente no âmbito dos movimentos populares, das organizaçóes socialistas e anarquistas, do sindicalismo e do cooperativismo, propícias para materializar a descentralização do poder, o compromisso cívico e a socialização de bens e riquezas.

Compartilhar os serviços públicos com as comunidades é uma diretriz que vai ao encontro das preocupaçóes apontadas por Thomas Piketty. O welfare state do século XXI está diante de uma encruzilhada: as demandas sociais ao Estado Social são elevadas, mas é impensável que a carga tributária possa crescer neste século nos índices do século passado, passando, por exemplo, da faixa de $40 \%$ a $50 \%$ à faixa de $70 \%$ ou $80 \%$, num contexto de baixo crescimento futuro. É preciso inovar e, convergente com a visão comunitarista, Piketty (2014, p. 470) assinala que a participaçáo de organizaçóes sociais na prestação de serviços deve ser incentivada e que "novas formas de organização e propriedade estáo para ser inventadas".

As diretivas da concepçáo comunitarista do Estado estão em consonância com o princípio da subsidiariedade. O Estado deve dedicar-se às tarefas que estão acima das condiçôes de alcance dos indivíduos, famílias e comunidades. E "todas as competências que não são imperativamente detidas pelo Estado, devem ser transferidas à coletividade" (BARACHO, 1996, p. 31) As iniciativas dos cidadãos e das comunidades na esfera local são valiosas como capacitação cívica para assumir responsabilidades coletivas, para melhor prestação dos serviços e para evitar a excessiva dependência estatal. Ao Estado compete acompanhar e apoiar essas iniciativas, numa lógica de complementaridade entre a ação comunitária e a ação estatal.

Nos países do capitalismo central, a ênfase comunitarista recai sobre a renovação do welfare state, contemplando a preocupação acerca de excessos, recuos ou fracassos estatais (ADÁN, 2008). Nos países emergentes e da periferia capitalista, o debate centra-se na afirmação e consolidação do paradigma welfarista. Aqui, a preocupação é a desigualdade social e o anseio é avançar rumo à democracia inclusiva, visando chegar ao patamar de benefícios sociais já alcançados há décadas nas 
sociedades desenvolvidas sem incidir no excessivo estatismo. Em comum, a necessidade da ação sinérgica do Estado, comunidade e mercado.

\section{O papel do mercado}

Em sentido amplo, o mercado é um espaço de troca entre produtores e compradores, de compra e venda, que remonta ao surgimento da divisão do trabalho. A partir da revolução industrial, o mercado adquiriu contornos radicalmente novos, de complexidade e impacto inéditos na vida social, tornando-se a forma econômica dominante em praticamente todo o mundo. Considerada geralmente como sinônimo de capitalismo, a economia de mercado moderna está no centro dos debates econômicos, cujas concepções mais conhecidas são o liberalismo, com sua defesa do livre mercado, e o marxismo, com sua crítica radical do mercado capitalista. A teoria econômica comunitarista, a socioeconomia (socio-economics), distingue-se de ambas.

O liberalismo econômico empenhou-se em mostrar que o mercado autorregulado, livre, com o mínimo de interferência estatal, é o melhor caminho para a prosperidade. A metáfora da mão invisivel, de Adam Smith, e a expressão vícios privados, beneficios públicos, de Bernard de Mandelville, expressam a fé liberal na capacidade da simples interação de agentes econômicos individuais, cada qual pensando apenas no seu próprio interesse, conduzir à harmonia social. A longa tradição liberal, incluído o neoliberalismo, professa a fé nas virtudes do mercado e da iniciativa privada (privatismo).

O marxismo, por outro lado, considera o mercado capitalista como um modo de produção intrinsecamente injusto. A exploração dos donos dos meios de produçâoo sobre os trabalhadores seria a fonte de alienação, desigualdades, exclusão e instabilidade social. O capital - uma força extraordinária, contraditória e totalitária que subjaz a todas as relaçóes sociais - é o coração e o propulsor do mercado capitalista, que tende a transformar tudo em mercadoria. As contradiçóes insanáveis do capital explicam as crises do capitalismo. Daí a necessidade da erradicação do mercado e sua substituição pela economia planificada e pela propriedade pública dos meios de produção. $\mathrm{O}$ socialismo real do século $\mathrm{XX}$ evidenciou que o marxismo ortodoxo havia assumido a fé no Estado como condutor da economia e da vida social (estatismo) (BUBER, 2006).

Há um elemento comum a essas duas tradiçôes: o economicismo, ou seja, a hipervalorização da dimensão econômica na interpretação da vida em sociedade. $\mathrm{O}$ comunitarismo recusa o viés economicista em favor da ideia de intercausalidade das dimensóes, ressaltando o papel da cultura e dos valores. A socioeconomia - cujos fundamentos foram estabelecidos por Etzioni (2007) na sua obra The moral 
dimension: toward a new economics - em contraposição à escola neoclássica, rejeita a ideia de que o mercado é uma esfera separada ou independente. Coerente com o paradigma sociopolítico (ou paradigma eu-nós), a socioeconomia apoia-se em três postulados centrais: (i) as pessoas têm duas fontes de valoração: o prazer e a moralidade; (ii) a unidade de tomada de decisôes não é o indivíduo isolado: são as coletividades sociais, e nelas os valores e emoçôes desempenham importante papel; (iii) o mercado e a economia são um subsistema da sociedade, da política e da cultura. O mercado está imerso numa cápsula social, ou seja, está envolto pelos valores vigentes na sociedade.

Cinco aspectos são próprios da concepção comunitarista do mercado. Primeiro: o mercado regulado é a melhor alternativa para as sociedades atuais, preferivel ao livre mercado e à economia centralizada. Charles Lindblom (2002) assinala que desde a revoluçáo industrial o mercado é o maior sistema de coordenaçáo do comportamento humano, englobando milhóes de pessoas em todo planeta. Distinto do que ocorre em uma planificação centralizada, no mercado os indivíduos e as organizaçôes interagem por ajustes mútuos, sem uma autoridade central. No mercado realmente existente, o Estado é o principal comprador, um ofertante de produtos e serviços em larga escala através de empresas estatais, interventor ativo mediante proibição de certos tipos de venda e de subvençôes a grande parte das empresas privadas, além de ser um poderoso agente financeiro. As escolhas pessoais no mercado nada têm a ver com opções livres e voluntárias; as escolhas são controladas pelos processos descentralizados de compra e venda (LINDBLOM, 2002). Diferente de Marx, a concepçáo comunitarista náo considera o mercado a fonte de todos os males, nem vê a estatização da economia como solução para as suas mazelas. Nada há de degradante em vender e comprar bens, nem em colocar um valor nas coisas, diz Michael Walzer (2003). O livre intercâmbio de mercadorias é um traço importante da vida democrática. O problema está no imperialismo e na tirania do mercado, na tendência do dinheiro avançar em esferas nas quais não deve adentrar. Embora suas falhas sejam indiscutíveis, o mercado é uma perna indispensável do tripé que caracteriza a boa sociedade, de modo que as sociedades da Terceira Via reconhecem que "o mercado é o melhor motor para a produção de bens e serviços, para o trabalho e, portanto, para o emprego e para o progresso econômico" e que o setor privado "pode alentar a inovaçáo, elemento essencial para que a economia se adapte às condiçôes e às oportunidades em contínua mudança” (ETZIONI, 2001a, p. 86).

Segundo: a regulação estatal do mercado é indispensável. A socioeconomia insiste nos vínculos da economia com a política e com o Estado, entendendo a regulação estatal como necessária não só para assegurar direitos e proteção social aos 
cidadãos como também para o funcionamento do próprio mercado. Em linha com Karl Polanyi (2000), Etzioni (2009a) alerta que o livre mercado é uma ficção liberal. Se houve algo como um sistema econômico dirigido pelos preços de mercado, resumiu-se ao período de meados do século XIX ao início do século XX, o qual não perdurou em função de indesejáveis consequências sociais. A história mostra, segundo Polanyi, que o mercado requer a presença do Estado, posição compartilhada por Etzioni, para quem o mercado é incapaz por si próprio de solucionar seus conflitos e de prover instrumentos de defesa das pessoas diante das forças econômicas. Um governo regulador, que esteja a serviço do interesse coletivo, é indispensável ao bom funcionamento do mercado e à saúde social. Todavia, as regulaçôes não são inerentemente boas. Podem ser excessivas, vazias ou a serviço de interesses particulares. Estabelecer mecanismos adequados de regulaçáo é um dos desafios políticos permanentes das boas sociedades (ETZIONI, 2009a).

Terceiro: a economia e o mercado refletem os valores vigentes na sociedade. A conexão entre moral e economia é um dos elementos nucleares da socioeconomia. $\mathrm{O}$ mercado está imerso numa cápsula social. As transaçôes que acontecem no mercado e as formas de competição entre os agentes e grupos econômicos são influenciadas fortemente pelos valores dominantes na sociedade. A competição é intrínseca ao mercado; é uma forma de conflito oriunda de interesses e objetivos divergentes dos indivíduos, que postos juntos nunca constituem um conjunto harmonioso. Por isso, são requeridos mecanismos para controlar e proteger a competiçáo, pois deixada a si pode chegar à autodestruição. $O$ contexto social não apenas restringe, mas é precondição para o funcionamento da competição. A competição adequadamente limitada é uma força construtiva; a competição desatada é destrutiva; a competição reprimida inibe a criatividade (ETZIONI, 2007).

Quarto: o mercado capitalista vem acarretando impactos fortemente negativos na vida social. $\mathrm{O}$ enaltecimento do egoísmo e do consumo fácil tem sido característica das recentes décadas de euforia neoliberal e do triunfalismo do mercado (ETZIONI, 2009a). Robert Bellah (1996) alerta para os severos impactos da cultura individualista sobre a ecologia social, levando à destruição de laços tênues que unem os seres humanos uns aos outros, tornando-os temerosos e isolados. Michael Sandel (2012, p. 16) faz admoestação severa sobre os limites morais do mercado: nas últimas décadas "fomos resvalando da situaçáo de ter uma economia de mercado para a de ser uma sociedade de mercado". Cita como exemplos preocupantes as escolas, hospitais, prisôes e serviços de segurança orientados por critérios de lucro; a terceirização da guerra e da gravidez; a venda do direito de poluir; os sistemas de financiamento eleitoral; a utilização do próprio corpo para anúncios publicitários; o comércio de 
órgãos humanos, entre outros. $\mathrm{Na}$ mesma linha vai a avaliação de Benjamin Barber (2009): o capitalismo tardio, movido pelo consumismo, caracteriza-se por corromper crianças, infantilizar adultos e engolir cidadãos. Sua dinâmica não está assentada na produção de mercadorias, e sim na de necessidades. É um capitalismo incompatível com a democracia. Um modo de vida condizente com valores comunitários requer bloqueios ao poder do dinheiro, acrescenta Michael Walzer (2003): não se pode comprar nem vender seres humanos; influência política; justiça criminal; liberdade de expressão, de imprensa, de religiáo e de associação; direitos de casamento e procriação; afastamento da comunidade política; dispensa de serviço militar, júri e trabalhos comunitários; cargos políticos; proteção policial, educação básica e serviços sociais básicos; os intercâmbios desesperados no trabalho; prêmios e títulos honoríficos; graça divina; amor e amizade; e vendas criminosas.

Quinto: o mercado capitalista possibilita, mas limita o alcance da democracia. A democracia moderna só existiu até hoje em países com economia de mercado, mas em meio a conflitos permanentes. A descentralização econômica do mercado favorece a descentralização política da democracia, mas ao mesmo tempo cria uma série de dificuldades, como as desigualdades econômicas, que induzem à desigualdade política (DAHL, 2009). Um nível superior de democracia requer outra forma de mercado, que possibilite o que John Dewey (2004) denomina de passagem da Grande Sociedade para a Grande Comunidade. A democracia representativa, forjada no contexto industrial e tecnológico, abriga um público disperso, móvel e múltiplo, num ambiente marcado pelo individualismo e pela desagregação. Um estágio superior será aquele em que um público bem informado, articulado e organizado realizar o ideal da democracia como sinônimo de vida comunitária: "a democracia alcançará seu pleno sentido, pois democracia é uma palavra que denota uma vida de comunhão livre e enriquecedora" (DEWEY, 2004, p. 156).

Sexto: um novo mercado é possivel e necessário. A forma conhecida de mercado, aquela que se consolidou a partir da revolução industrial, e vige até hoje, é o capitalismo, caracterizado pelo predomínio da propriedade privada. O capital é a expressão de relaçóes econômicas em que o resultado econômico (lucro) é predominantemente apropriado por proprietários privados, que reinvestem o lucro na expectativa de maximizar seus ganhos. É indiscutível que o capitalismo liberou um extraordinário caudal de energias ligadas aos impulsos, desejos e anseios individuais, e foi a mola propulsora do crescimento econômico dos últimos dois séculos, mas também é indiscutível que o capitalismo das últimas décadas, marcado pela financeirização e pelo consumismo exacerbado, disseminado pela globalização, é um sistema insustentável. A alternativa a esse sistema capitalista não é a economia 
centralmente planificada. Não basta mudar as estruturas econômicas: a expectativa de que a objetivação do ser humano poderia ser superada "se o controle dos novos meios de produção passasse à coletividade se mostrou falsa. Pelo contrário, resultou numa objetivação maior em outros terrenos, para além da produção" (ETZIONI, 1980, p. 10). A alternativa ao capitalismo insustentável é a regulaçáo e o controle social do mercado, que recupere a soberania democrática, uma tarefa enorme a ser construída global e localmente (BARBER, 2009, p. 276). Somente a sociedade ativa é capaz de autocontrole social, dominando as forças econômicas que subjugam os indivíduos. $\mathrm{O}$ mercado regulado e controlado socialmente não é o caminho da completa igualdade entre os seres humanos, como na utópica comunidade perfeita de Marx, mas da igualdade complexa, a ser construída diuturnamente em cada dimensão social (WALZER, 2003).

\section{Comunidade, sociedade civil e terceiro setor}

A relevância da comunidade para a boa sociedade - um tema ignorado por grande parte da filosofia e ciência política - é a ideia central do comunitarismo. Enquanto os liberais acreditam nas virtudes do livre mercado e os socialconservadores nas virtudes do bom Estado, os comunitaristas acreditam nas virtudes da boa sociedade (ETZIONI, 2004). O comunitarismo destaca-se por afirmar que a esfera comunal é uma terceira esfera, uma esfera específica, distinta do público estatal e do mercado (BARBER, 2000).

Historicamente, a comunidade é anterior às outras esferas. Michael Taylor (1982) recorda que a humanidade viveu sem Estado e sem mercado ao longo de dezenas de milhares de anos; e nesse período, as comunidades foram a base da vida social, organizando a economia e os serviços indispensáveis a todos. Na trajetória humana desde o surgimento do homo sapiens, há mais de 100 mil anos, a comunidade foi vital para a sobrevivência dos homens, enquanto o Estado e o mercado são extremamente recentes, não passando de três séculos sua conformaçáo moderna. Assim, a retrospectiva histórica nos autoriza a pensar o futuro da vida humana sem a esfera estatal e mercantil, mas não sem a esfera comunal.

A predominância de formas de vida baseadas no Estado e no mercado, no período moderno, vem trazendo obstáculos de grande envergadura ao protagonismo cidadão nos assuntos públicos. As formas de organização política e econômica são irresponsivas, afastam os cidadãos das decisóes e geram alienação. Como reação, a grande maioria dos cidadáos acaba investindo sua energia em coletividades e comunidades. Mas, "latente nas moléculas sociais, as coletividades, há suficiente energia para uma ampla realização de valores”, acredita Etzioni (1980, p. 11). É 
possível passar da sociedade irresponsiva à sociedade ativa, o que requer que cidadáos e comunidades transformem em energia pública uma parte da energia que empregam nas tarefas privadas. Uma sociedade ativa tem características próximas às da pólis grega "na intensidade e amplitude de sua vida política", investindo "maior proporção de recursos na ação política", e nela a reflexão intelectual tem "uma posição mais elevada, mais pública" (ETZIONI, 1980, p. 11). A autêntica transformação social só se alcança mediante uma profunda transformação de valores públicos e pessoais. Aí está a grande contribuição das comunidades: a transformação de valores só é possível na esfera da comunidade, por ser o âmbito de construção e reconstrução permanente de valores.

A dúvida levantada por inúmeros estudos é se, diante da onda individualista e do recuo das comunidades tradicionais, as comunidades têm condiçóes de desempenhar um papel significativo na renovação moral das sociedades. Essa dúvida remonta ao final do século XIX, a partir da tematizaçáo de Ferdinand Tönnies (2009), na sua clássica obra Gemeinschaft und Gesselschaft, da profunda mudança de relaçóes sociais na passagem do feudalismo ao capitalismo. Através do contraste entre comunidade e sociedade (ou associaçâo), Tönnies mostrou que em lugar das relaçóes de intimidade, coesão social, compromisso moral e continuidade no tempo (comunidade), nas sociedades urbanas nascentes predominavam as relaçóes impessoais, competitivas e baseadas no contrato (sociedade/associaçáo). A partir de entâo, parte importante dos estudos sociológicos passou a trabalhar com a ideia de que a fragmentação social, o individualismo e a expansão do welfare state relegaram as comunidades a um papel marginal na vida social.

Os comunitaristas não concordam com essa leitura, assim como Michel Maffesoli e outros autores. Maffesoli (1998) assinala que o ambiente da socialidade pós-moderna, marcada pelo hedonismo, caracteriza-se pelo constante surgimento de microgrupos, tribos esportivas, sexuais, religiosas e outras, organizadas em torno de interesses e afinidades que proporcionam o sentimento de pertença e apoio que os indivíduos não encontram em instituiçóes como o Estado, os partidos e os sindicatos. Nas grandes cidades, há uma multidão de aldeias, que se entrecruzam, se opõem e se entreajudam, e cujo entrelaçamento constitui uma rede, em constante mutação, sem nenhum centro definido. O paradigma da rede é "a reatualização do antigo mito da comunidade” (MAFFESOLI, 1998, p. 208).

Uma rápida retrospectiva histórica ilustra a concepção comunitária. As comunidades são fenômenos milenares, que acompanham a trajetória humana desde os primórdios. Aldeias, tribos, clâs, guildas, cidades, comunas, mosteiros, burgos, condados e distritos são formas comunitárias do mundo pré-industrial, que 
desempenharam um papel fundamental na economia e na proteção social. Antes que houvesse Estado e economia de mercado, as relaçóes econômicas eram mediadas pelas relações comunitárias. A provisão comunitária (cuidados com a saúde, a educação, a infância e a velhice) estava ao encargo das famílias e comunidades. Nas sociedades agrárias, as afinidades comunitárias estavam vinculadas ao território e à vizinhança. $\mathrm{O}$ surgimento do capitalismo assinalou a crise dessas comunidades tradicionais. Mas, ao invés da desaparição, o que ocorreu foi uma mutação do fenômeno comunitário: as comunidades passaram a se construir menos por vizinhança e mais por outras afinidades, ligadas ao trabalho, à religião, à política, à cultura, à etnia, ao gênero, entre outras ${ }^{2}$.

Do ponto de vista da proteção social, se o welfare state absorveu muitas atividades antes desempenhadas pelas famílias e por organizaçóes sociais (na saúde, educação, administração da justiça, disciplinamento das relaçôes de trabalho, entre outras), isso não significou a extinção dos corpos sociais intermediários. A constituiçâo de uma robusta sociedade civil e o crescimento do chamado terceiro setor em grande parte dos países ocidentais, na segunda metade do século XX, evidenciou que os organismos comunitários são insubstituíveis em múltiplas funçôes sociais. Em grande parte dos países desenvolvidos é usual a incorporação da sociedade civil em políticas públicas. $\mathrm{Na}$ Inglaterra, por exemplo, há uma importante tradição de políticas comunitárias em áreas como saúde, juventude, artes, empresas, policiamento e governo comunitário (BUTCHER e MULLARD, 1993). Nas últimas décadas, as alternativas para a crise do modelo estatista do Estado de Bem-Estar nos países europeus passam, segundo estudiosos como Piearpaolo Donati (1999), pelo compartilhamento dos serviços públicos com as organizaçôes sociais e as famílias.

O que distingue a comunidade em relação a outros grupos humanos são os vínculos de coesão, intimidade e continuidade no tempo, decorrentes do compartilhamento de valores, tradiçóes e crenças. Etzioni insiste em dois os aspectos:

\footnotetext{
${ }^{2}$ Nem todas as formas de estar junto são verdadeiras comunidades. A efemeridade é uma marca importante do tribalismo, analisado por Michel Maffesoli (1998). Estar junto de outros seres humanos é exigência natural da espécie humana; viver em comunidade requer vínculos, assinala Dewey (2004). Muitas formas não passam de encontros efêmeros, sem compromisso nem continuidade, meros simulacros da autêntica vida comunitária, que Bauman (2003) denomina de comunidades estéticas.
} 
Comunidade é uma combinação de dois elementos: (a) Uma rede de relaçóes carregadas de afeto entre um grupo de indivíduos, relaçóes que frequentemente se cruzam e se reforçam umas às outras (em vez de tão somente relaçóes individuais, uma a uma ou encadeadas), (b) Uma medida de compromisso com um conjunto de valores compartilhados, normas e significados, e uma história e identidade compartilhadas - em resumo, com uma cultura particular (ETZIONI, 2001b, p. 142-143).

Michael Taylor (1982) apresenta um conceito similar: a comunidade se caracteriza pelo (i) compartilhamento de valores e crenças, (ii) relaçóes diretas (ao invés de representativas) e multifacetadas entre os membros, e (iii) reciprocidade, através de formas de cooperação e distribuição.

Assim concebida, a comunidade constitui uma esfera da vida social específica, distinta do mercado e do Estado. É impróprio incluir a comunidade na esfera privada (geralmente associada ao mercado), assim como é indevido incluí-la na esfera estatal. A esfera comunal é ampla: "inclui relaçôes entre membros de famílias nucleares e extensas; teias de amizades; redes de afinidade em comunidades residenciais, étnicas, raciais, religiosas, profissionais e outras; e milhares de associaçôes voluntárias e corporaçôes sem fins lucrativos" (ETZIONI, 2013, p. 62). Universidades, centros médicos, instituiçôes culturais e assistenciais, e uma grande variedade de organizaçóes civis estão compreendidas na esfera comunal.

Sociedade civil e terceiro setor são conceitos que guardam forte relação com o de comunidade. O conceito de terceiro setor aqui assumido compreende as organizaçóes criadas e mantidas pelos cidadáos para atender necessidades e anseios coletivos, sem cunho mercantil voltado ao lucro individual, nem imerso no aparato estatal. O terceiro setor é o conjunto de organizaçóes criadas e mantidas pela sociedade civil (ou comunidade), que proporcionam bens e serviços de interesse comum e cujos resultados são apropriados coletivamente. É, portanto, um conjunto mais vasto do que as chamadas organizaçôes sem fins lucrativos (ONGs), incluindo fundações, associações, entidades sem fins lucrativos, cooperativas, sindicatos e outras organizaçôes da sociedade civil. $\mathrm{O}$ terceiro setor é distinto do setor privado: não deve ser analisado como um mero subproduto que resulta das falhas do mercado e do Estado, nas palavras de Vasco Almeida (2011), e sim um elemento central na estrutura de governação das sociedades contemporâneas.

Sociedade civil é um conceito político com trajetória específica, mas convergente em relação ao de comunidade, por abranger as diferentes formas de ação social e de participação cidadá nas decisóes públicas. Refere-se ao papel exercido por bairros, escolas, congregaçóes religiosas, sindicatos e outras organizaçóes na vida 
política e social. Barber (2000) caracteriza a sociedade civil como o domínio do diálogo civil. Charles Taylor (2000) a conceitua como o âmbito das associaçóes autônomas livres da tutela estatal e com vocação pública. A sociedade civil e o terceiro setor são importantes elementos da cidadania nos dias atuais. Walzer (1977) lembra que o compromisso com a comunidade política e o pertencimento a grupos e associaçóes asseguram as características centrais da cidadania, que são a proteção e a responsabilidade. Sandel (2008) afirma que uma sociedade civil sã fomenta a civilidade, mas também inspira costumes, qualidades de caráter e costumes dos cidadãos democráticos.

Etzioni avança uma tese arrojada: a esfera comunal é a grande responsável pelas principais mudanças nas outras esferas, a estatal e privada. O Autor já assinalava na década de 1970 a aproximaçáo entre as esferas pública e privada num movimento rumo a um terceiro setor, prevendo que o mesmo poderia ser "a mais importante alternativa para as próximas décadas, não por substituição dos outros dois, mas por combinar e balancear seus importantes papeis" (ETZIONI, 1973, p. 314). Contrapondo-se à atuaçáo fragmentada, citava exemplos próprios da realidade norteamericana da época em que ilustravam as vantagens do terceiro setor e da cooperação intersetorial: o seguro de saúde, o crédito estudantil, o serviço postal, o projeto Apollo (da NASA), as universidades e hospitais administrados pela sociedade. O exame empírico das grandes mudanças, nas esferas pública e privada, mostra, segundo o autor, que as mudanças vão na direçáo assinalada há quatro décadas, impulsionadas por forças que não pertencem nem ao reino público estatal nem ao privado, e sim pertencem a um terceiro reino, a comunidade ou sociedade civil. A maior força comunal propulsora de mudanças são os movimentos sociais - de libertação nacional, socialistas, religiosos, ambientais, de direitos humanos e outros. A força desses movimentos está em "retirar legitimidade e apoio político a regimes em declínio e lançar os fundamentos para um novo, processo que afeta tanto a esfera privada quanto a pública" (ETZIONI, 2013, p. 63). Por isso, é imperioso suplantar o esquema que opóe o público ao privado pela compreensáo de que esses reinos estáo entrelaçados (intertwined). As melhores soluçôes para os desafios sociais estáo na articulação entre o setor governamental, o setor privado e o terceiro setor.

As comunidades são altamente importantes na vida social também por outro aspecto: os benefícios individuais da vida comunitária. Grande parte da filosofia social moderna partilha a visão de que o predomínio da orientação instrumental nas relaçôes sociais é uma das maiores ameaças ao bem-estar das pessoas. Resultados de pesquisas da psicologia trazem amplas evidências em favor desse ponto de vista. As investigaçóes conduzidas por John Cacioppo e William Patrick (2010) corroboram 
fartamente a tese de que a solidão (a dor decorrente da ausência de vínculos sociais significativos) é uma das principais causas de doenças em nossos dias. A solidão aparece associada ao sentimento de infelicidade, à incidência de divórcios, de problemas de relacionamento familiar, dores, consumo de álcool, obesidade, doenças, aceleramento do declínio físico, envelhecimento, mal de Alzheimer, incapacidade de pensar com clareza, disfunçôes cardiovasculares, doenças cerebrovasculares e circulatórias, respiratórias, gastrointestinais e câncer. A solidão, segundo os autores, está em pé de igualdade com pressão sanguínea alta, obesidade, falta de exercício e tabagismo como fator de risco para doenças e morte precoce.

Fortalecer as comunidades é o melhor meio para enfrentar esses males. Quem vive em comunidade sofre menos dos males da solidão, está mais bem protegido contra os riscos da criminalidade, o tratamento de drogas e álcool é mais eficaz desenvolvido a partir das comunidades e os cuidados de crianças e idosos apresentam melhores resultados (ETZIONI, 2001a). A participação das comunidades nas políticas públicas caracteriza as políticas comunitárias, importantes em vários países, como no Reino Unido, incluindo programas sociais voltados ao cuidado de crianças, de idosos, de saúde, de segurança, de emprego (BUTCHER e MULLARD, 1993). Isso tudo nos leva a poder concordar com a afirmativa de Etzioni (2001a, p. 30) de que "as comunidades podem chegar a ser a mais importante nova fonte de serviços sociais no futuro previsível”. Não que as comunidades possam substituir os serviços prestados pelo Estado: o caminho é a ação combinada de modelos híbridos, sinérgicos, incluindo agências estatais, comunidades e organizaçôes privadas.

\section{Comunitarismo e capital social}

A tese comunitarista do equilíbrio entre Estado, comunidade e mercado está envolta pela concepção democrática. Não se trata da democracia procedimental, concepção que vê a democracia como seleção das elites governantes pelo voto. Para os comunitaristas responsivos, não bastam regras e procedimentos institucionalizados, que assegurem eleiçóes periódicas e o regular preenchimento dos cargos com base na vontade da maioria. Comunitaristas não são majoritários, diz a plataforma do movimento, pois estão comprometidos com a construção de uma democracia forte, amparada numa cultura política que equilibra direitos e responsabilidades, com forte senso de participaçáo cívica e valores republicanos (THE COMMUNITARIAN NETWORK, 1991).

A democracia forte é principalmente cidadania forte, participação e comunidade cívica robustas, cuja construção requer dos indivíduos que invistam uma parte das energias que usualmente concentram na dimensão privada (BARBER, 
1996). Construir espaços de participação dos cidadãos nos assuntos públicos em tempos pós-modernos é um desafio imenso, reforça Charles Taylor (2000). A alienação dos cidadãos em meio ao emaranhado de regras e instituiçóes políticas irresponsivas e a tendência de fragmentação dos indivíduos devem ser enfrentadas pela constituição de uma esfera pública, um espaço comum em que as pessoas "se congregam, por meio de uma variedade de meios (impressos, eletrônicos), bem como em encontros diretos para discutir questôes de interesse comum". Não se trata propriamente de uma e sim de "uma multiplicidade de esferas públicas aninhadas no interior de outras", de forma que as esferas públicas locais possam influir no debate nacional (TAYLOR, 2000, p. 277).

A concepçáo política dos comunitaristas, e em especial sua ênfase no papel dos valores morais, das normas sociais, da educação e da persuasão, é convergente com a perspectiva dos estudos da cultura política e do capital social, cujos estudiosos frisam o papel vital da dimensão cultural e das atitudes de confiança e cooperação para a solidez democrática. Desde Almond e Verba (1965) sabe-se que os traços culturais variam de um país a outro, de uma região a outra, e que não há um único padrão cultural democrático. Países com larga tradição de estabilidade das instituiçóes democráticas proporcionaram a consolidação de atitudes democráticas no transcurso de várias geraçôes, enquanto países com pouca vivência da democracia, como o Brasil, defrontam-se com o desafio de assegurar uma socialização política continuada para a incorporação de tais atitudes (BAQUERO, 2003).

A presença de capital social (conjunto de redes, relaçôes e normas que facilitam ações coordenadas na resolução de problemas coletivos e que proporcionam recursos que habilitam os participantes a acessarem bens, serviços e outras formas de capital) tem sido apontada pela literatura internacional como fator de fortalecimento da democracia, do desenvolvimento e do combate à pobreza (PUTNAM, $1996 \mathrm{e}$ 2002; ATRIA e SILES, 2003).

Comunitaristas e estudiosos do capital social partilham a ideia de que política e economia estão envoltos em valores, crenças e atitudes ${ }^{3}$. Desse modo, a intensidade da vida comunitária tem correspondência com a intensidade do capital social. Vida comunitária intensa e elevado estoque de capital social favorecem tanto a eficácia governamental quanto o progresso econômico. É nas comunidades que são criados e

\footnotetext{
${ }^{3}$ Etzioni (2005) faz uma ressalva à abordagem do capital social desenvolvida por Putnam: o discurso sobre a civilidade e as virtudes da sociedade civil não é suficiente, devendo ser complementado pela consideração dos valores morais. Organizaçóes sociais que difundem valores democráticos e cooperativos trazem uma contribuição efetiva à boa sociedade, o que não acontece com organizaçôes marcadas por valores particularistas e discriminatórios.
} 
recriados os valores morais, as convicçóes que subjazem à ação dos indivíduos, que os levam a agir de forma conflituosa ou buscando o consenso. Os conflitos são intrínsecos à vida humana e estão presentes nas próprias comunidades. Não é possível nem desejável suprimi-los. O que é próprio da comunidade é o tratamento dos conflitos no interior de um ambiente que reforça vínculos, compromissos e valores comuns.

A educação cívica e a educação moral cumprem papel relevante na transformação social. A formação do caráter é apontada pelos comunitaristas como a tarefa central da educaçáo básica, e, tanto na forma quanto no conteúdo, o ambiente escolar deve ser propício para reforçar valores democráticos. Os esportes coletivos são espaços nobres de formação para a disciplina e a cooperação. Não se trata de disseminar valores particulares de grupos, religióes ou comunidades, e sim valores que estão na base da vida nacional, reconhecidos constitucionalmente, como a dignidade de todas as pessoas, o respeito às diferenças, a resoluçáo pacífica dos conflitos, a responsabilidade de todos com o patrimônio público e assim por diante (THE COMMUNITARIAN NETWORK, 1991; ETZIONI, 1999). A prática do compromisso político é de grande valia: o serviço comunitário e a dedicaçáo a causas voluntárias têm efeitos educativos de grande alcance (BARBER, 2000).

Comunitaristas e estudiosos do capital social tem em comum a defesa da descentralização política, expressa no princípio de subsidiariedade - deixar que as pessoas, as comunidades e as organizaçóes intermediárias façam o que estiver ao seu alcance, atendo-se o Estado a realizar o que estiver acima desse nível. A descentralização e a subsidiariedade implicam em devolver à esfera comunal parte do que as esferas estatal e mercantil apropriaram ao longo do tempo, devolução que se justifica na medida em que a comunidade possui meios mais poderosos (a persuasão, a educação, a liderança) para a realização de aspectos do bem comum do que a coerção ou o auto interesse.

O enfoque comunitário e de capital social estão diante de um mesmo risco: o localismo, ou seja, o foco exclusivo no espaço local e nas relaçóes de proximidade, mais favoráveis ao senso de confiança interpessoal. No mundo globalizado, a construção de vínculos comunitários locais não pode estar dissociada de açóes de amplo alcance, próprias das esferas de poder nacional e internacional. $\mathrm{O}$ viés localista deixa as comunidades despreparadas diante da dinâmica da globalizaçáo. Trata-se de articular o local com o global e combinar a descentralização das açôes com a intersetorialidade e a coerência, indispensáveis às políticas públicas. 


\section{Considerações finais}

O paradigma comunitarista proporciona uma abordagem inovadora sobre a interrelaçáo entre Estado, comunidade e mercado, que é convergente com os pressupostos do capital social. Teorias políticas focadas unilateralmente na força coerciva do Estado, ou no autointeresse que rege as relaçóes do mercado, são impermeáveis ao capital social. O comunitarismo supera as concepçóes unilaterais em favor de uma perspectiva de sinergia e complementaridade e confere grande relevância à dimensão da cultura e dos valores.

O papel político da sociedade civil e do terceiro setor é realçado no paradigma comunitarista. Reconhece-se a especificidade das organizaçóes do terceiro setor, classificando-as como uma categoria distinta do público e do privado, e capazes de assumir parcela dos serviços públicos, especialmente nas políticas sociais.

Ao postular o fortalecimento das comunidades, o comunitarismo não desconhece o protagonismo da ação estatal: um Estado forte, regulador e prestador de serviços, é indispensável à boa sociedade. Por outro lado, reconhece o dinamismo do mercado na produção de bens e serviços, sendo necessária a regulação moderada.

Comunitarismo e capital social convergem nos seus pressupostos. A boa sociedade só é possível mediante a ação permanente de cidadãos ativos, sob o impulso de valores cívicos e morais orientados à democracia e à inclusão social.

João Pedro Schmidt é Professor titular da Universidade de Santa Cruz do Sul - UNISC, no Programa de Pós-Graduação em Direito. Mestre em Filosofia Política e Doutor em Ciência Política pela Universidade Federal do Rio Grande do Sul - UFRGS. E-mail: jpedro@unisc.br.

\section{Referências}

ADÁN, José P. Adiós estado, bienvenida comunidad. Madrid: Eiunsa, 2008.

ALMEIDA, Vasco. Estado, mercado e terceiro setor: a redefiniçāo das regras do jogo.

Revista Crítica de Ciências Sociais, Coimbra, v. 95, p. 85-104, dez. 2011.

ATRIA, Raul; SILES, Marcelo (Comp.). Capital social y reducción de la pobreza en América Latina y el

Caribe: en busca de un nuevo paradigma. Santiago: CEPAL/University of Michigan Press, 2003.

ALMOND, Gabriel; VERBA, Sidney. The civic culture. Standford: Little Brown, 1965. 
BAQUERO, Marcello. Construindo uma outra sociedade: o capital social na estruturação de uma cultura política participativa no Brasil. Revista de Sociologia e Política, Curitiba, v. 21, p. 83-108, nov. 2003.

BARACHO, José Alfredo. O princípio da subsidiariedade: conceito e evolução. Rio de Janeiro: Forense, 1996.

BARBER, Benjamin. Making democracy strong: a conversation with Benjamin Barber. The Civic Arts Review, v. 9, n. 3, 1996.

Un lugar para todos: cómo fortalecer la democracia y la sociedad civil. Barcelona/Buenos Aires: Paidós, 2000.

Consumido: como o mercado corrompe crianças, infantiliza adultos e engole cidadãos. Rio de Janeiro/São Paulo: Record, 2009.

BAUMAN, Zygmunt. Comunidade. Rio de Janeiro: Jorge Zahar, 2003.

BELLAH, Robert et al. Habits of the heart: individualism and commitment in American life. Berkeley/Los Angeles, USA: University of California Press, 1996.

BOSWELL, Jonatan. Community and the economy: the theory of public co-operation. London/New York: Routlege, 1990.

BUBER, Martin. Caminos de utopía. México: Fondo de Cultura Económica, 2006.

BUTCHER, Hugh; MULLARD, Maurice. Community policy, citizenship and democracy. In: BUTCHER, Hugh (Ed.). Community and public policy. London: Pluto Press, 1993. p. 217-240.

CACIOPPO, John; PATRICK, William. Solidão: a natureza humana e a necessidade de vínculos sociais. Rio de Janeiro: Record, 2010.

DAHL, Robert. Sobre a democracia. Brasília: Edunb, 2009.

DONATI, Pierpaolo. La ciudadanía societaria. Granada: Universidad de Granada, 1999.

DEWEY, John. La opinión pública y sus problemas. Madrid: Morata, 2004.

ETZIONI, Amitai. The third sector and domestic missions. Public Administration Review, v. 33, n. 4, p. 314-323, jul.-ago. 1973.

. La sociedad activa: una teoría de los procesos societales y políticos. Madrid: Aguilar, 1980.

. La nueva regla de oro: comunidad y moralidad en una sociedad democrática. Barcelona: Paidós Iberica, 1999. 2001a.

La tercera vía: hacia una buena sociedad. Propuestas desde el comunitarismo. Madrid: Trotta,

The monochrome society. Princeton/Oxford: Princeton University Press, $2001 \mathrm{~b}$.

The common good. Cambridge: Polity Press, 2004.

Por qué la sociedad civil no es lo suficientemente buena. Revista del CLAD Reforma y Democracia, Caracas, n. 33, p. 1-15, out. 2005.

El guardián de mi hermano: autobiografía y mensaje. Madrid: Astor Juvenil Palabra, 2006.

La dimensión moral: hacia una nueva economía. Madrid: Astor Juvenil Palabra, 2007.

The free market versus a regulating government. Challenge, v. 52, p. 40-46, jan.-fev. 2009a.

A crisis in consumerism. In: HEMERIJCK, Anton; KNAPEN, Ben; VAN DOORNE, Ellen.

Aftershocks: economic crisis and institutional choice. Amsterdam: Amsterdam University Press, 2009b. p. 55-62.

. The bankruptcy of liberalism and conservatism. Political Science Quarterly, v. 128, n. 1, p. 39-65, 2013.

. Communitarianism revisited. Journal of Political Ideologies, v. 19, n. 3, p. 241-260, 2014. 
GARGARELLA, Roberto. As teorias da justiça depois de Rawls. São Paulo: Martins Fontes, 2008.

LINDBLOM, Charles. El sistema de mercado. Madrid: Alianza Editorial, 2002.

MAFFESOLI, Michel. O tempo das tribos: o declínio do individualismo nas sociedades de massa. $2^{\text {a }}$ ed. Rio de Janeiro: Forense Universitária, 1998.

PIKETTY, Thomas. O capital no século XXI. Rio de Janeiro: Intrínseca, 2014.

POLANYI, Karl. A grande transformação: as origens da nossa época. 5a ed. São Paulo: Campus, 2000.

PUTNAM, Robert. Comunidade e democracia: a experiência da Itália Moderna. Rio de Janeiro: Ed. Getúlio Vargas, 1996.

- Solo en la bolera: colapso y resurgimiento de la comunidad norteamericana. Barcelona: Galaxia Gutenberg, 2002.

SANDEL, Michael. Filosofía pública: ensayos sobre moral en política. Barcelona: Marbot Ediciones, 2008.

- O que o dinheiro não compra: os limites morais do mercado. Rio de Janeiro: Civilização Brasileira, 2012.

SCHMIDT, João P. Comunidade e comunitarismo: consideraçóes sobre a inovação da ordem sociopolítica. Ciências Sociais Unisinos, São Leopoldo, v. 47, n. 3, p. 300-313, set.-dez. 2011.

- Amitai Etzioni e o paradigma comunitarista: da sociologia das organizaçóes ao comunitarismo responsivo. Lua Nova, Sáo Paulo, n. 93, p. 93-138, set.-dez. 2014.

SEVILHA, Jordi; QUIRÓS, Lorenzo B. Mercado o Estado? Dos visiones sobre la crisis. Barcelona: Deusto, 2010.

TAYLOR, Michael. Community, anarchy \& liberty. Cambridge: University of Cambridge, 1982.

TAYLOR, Charles. Argumentos filosóficos. São Paulo: Loyola, 2000.

THE COMMUNITARIAN NETWORK. The Responsive Communitarian Platform. 1991. Disponível em: <http://communitariannetwork.org/platform>. Acesso em: 30 jan. 2015.

TÖNNIES, Ferdinand. Comunidad y asociación. Granada: Comares, 2009.

WALZER, Michael. Das obrigaçôes políticas: ensaios sobre desobediência, guerra e cidadania. Rio de Janeiro: Zahar, 1977.

. Esferas da justiça: uma defesa do pluralismo e da igualdade. São Paulo: Martins Fontes, 2003.

Texto recebido em 15 de abril de 2015. Aprovado em 03 de agosto de 2015. 
